\title{
New emerging tasks for microRNAs in the control of $\beta$-cell activities
}

\author{
Claudiane Guay and Romano Regazzi \\ Department of Fundamental Neurosciences, University of Lausanne
}

\author{
Corresponding author: \\ Dr. Romano Regazzi \\ Department of Fundamental Neurosciences \\ Rue du Bugnon 9, 1005 Lausanne, Switzerland \\ Tel. ++412169252 80/Fax. ++41216925255 \\ E-mail: Romano.Regazzi@unil.ch
}




\begin{abstract}
MicroRNAs are key regulators of $\beta$-cell physiology. They participate to the differentiation of insulin-producing cells and are instrumental for the acquisition of their unique secretory properties. Moreover, they contribute to the adaptation of $\beta$-cells to conditions of increased insulin demand and, if expressed at inappropriate levels, certain microRNAs cause $\beta$-cell dysfunction and promote the development of different forms of diabetes mellitus. While these functions are increasingly better understood, additional tasks for these small non-coding RNAs have been recently unveiled. Thus, microRNAs are emerging as signaling molecules of a novel exosome-mediated cell-to-cell communication mode permitting a coordinated response of the $\beta$-cells to inflammatory conditions and to modifications in the insulin demand. These discoveries raise a number of important issues that once addressed promise to shed new light on the molecular mechanism governing the functions of the $\beta$-cells under normal and disease states.
\end{abstract}




\section{Introduction}

Insulin is a central player in the control of glucose utilization and disposal. Indeed, this metabolic hormone promotes the uptake of this carbohydrate by skeletal muscles and adipocytes. Moreover, it inhibits hepatic glucose production and stimulates glycogen synthesis. In mammals, insulin is produced by pancreatic $\beta$-cells, a group of highly specialized cells located within the islets of Langerhans. The secretion of the hormone is modulated by nutrients and is fine-tuned by the integration of hormonal and neuronal cues [1]. The amount of insulin that is released in the circulation is determined by the levels of free fatty acids, of certain amino acids and of glucose, which is the main physiological stimulus of $\beta$-cell exocytosis. Instead of binding to a receptor, glucose triggers the release of the hormone through the generation of metabolic signals. To achieve this goal, $\beta$-cells are equipped with a specific repertoire of metabolic enzymes ensuring a tight coupling between glucose metabolism and insulin secretion. In fully differentiated $\beta$-cells, the glycolytic products generated by glucose catabolism are preferentially driven to mitochondria for oxidative phosphorylation. The ATP generated by this reaction causes the closure of ATP-sensitive $\mathrm{K}^{+}$ channels and a consequent depolarization of the plasma membrane [2]. This in turn triggers the opening of voltage-gated $\mathrm{Ca}^{2+}$ channels and a rise in intracellular $\mathrm{Ca}^{2+}$ concentration, finally leading to insulin exocytosis.

The amount of insulin released by $\beta$-cells is precisely adjusted to match the momentto-moment organism needs, permitting to maintain blood glucose homeostasis and to avoid chronic hyperglycemia or life-threatening hypoglycemic episodes. The sensitivity of insulintarget tissues is not constant throughout the entire lifespan and tends to decrease during aging [3]. Moreover, insulin-target tissues become resistant to the action of the hormone during pregnancy or obesity [4]. The consequent rise in the insulin needs is normally compensated by an increase in the mass and in the secretory activity of $\beta$-cells [4]. Failure in this adaptive process can result in the release of insufficient insulin to control blood glucose levels, leading to chronic hyperglycemia and to the development of diabetes mellitus, a very common metabolic disorder that is currently estimated to affect almost 400 million people worldwide ( $\sim 8 \%$ of the adult world population). Due to population aging and a growing tendency to sedentary lifestyle and obesity, the number of individuals suffering from this disease is expected to further increase in the next decades.

An in depth understanding of the mechanisms governing the activities of $\beta$-cells under normal conditions and of those responsible for their failure under diabetic conditions is 
paramount for the discovery of novel innovative approaches to prevent or treat the disease. This has made the $\beta$-cells the focus of intense investigations since decades. Most of the studies carried out so far searched for modifications in the level of key protein-coding genes occurring in the islets of diabetes animal models. This led to the identification of fundamental $\beta$-cell genes that are dysregulated in diabetes conditions. The involvement of at least part of these genes in human diabetes was confirmed by the study of the causes of monogenic forms of diabetes and by the discovery of variants that increase the susceptibility to the disease [5]. However, protein-coding sequences represent only a tiny fraction of the human genome (about 2\%) and we now know that most DNA sequences can be transcribed to RNA. Thus, beside mRNAs, the human transcriptome contains a very large repertoire of RNA molecules with no protein-coding potential. It is now clear that at least part of these non-coding molecules play central regulatory roles in a wide variety of physiological and pathological processes. Non-coding RNAs fall in different categories according to their length, biogenesis, genomic origin, binding partners and mode of action. This review will focus on a particular class of non-coding RNAs, the microRNAs (miRNAs). For a detailed description of the properties and functions of other non-coding transcripts produced by $\beta$-cells we refer the reader to other recent reviews $[6,7]$.

\section{miRNAs as regulators of specialized $\beta$-cell functions}

MiRNAs are major regulators of gene expression. These small non-coding RNAs (21-23 nucleotides) function by partially pairing to the 3'untraslated region of target mRNAs, causing translational repression and/or a decrease in messenger stability [8]. Every miRNA can regulate many target genes and a specific target mRNA is often under the control of several distinct miRNAs. Thus, miRNAs form a complex regulatory network permitting the fine tuning of gene expression. The first evidence for an involvement of miRNAs in the control of $\beta$-cell activities was provided more than a decade ago by Poy et al. [9]. In this pioneering work, miR-375, a miRNA highly enriched in pancreatic islets, was demonstrated to inhibit the secretory activities of $\beta$-cells. Later on, the analysis of the phenotype of miR375 knockout mice revealed that this miRNA is also necessary for compensatory $\beta$-cell mass expansion under insulin resistance conditions [10]. Moreover, miR-375 was discovered to play an even more important role in pancreatic $\alpha$-cells. Indeed, miR-375 knockout animals display an increased $\alpha$-cell mass and elevated glucagon levels, resulting in chronic hyperglycemia. The knockout of other miRNAs that are very abundant in $\beta$-cells caused also major changes in insulin secretion and glucose homeostasis. Indeed, miR-7a was shown to 
target important components of the exocytotic machinery of $\beta$-cells and to act as a negative regulator of insulin secretion [11]. Overexpression of this miRNA resulted in impaired insulin release and in the development of diabetes. On the other hand, ablation of the members of the miR-200 family improved survival of $\beta$-cells under stress conditions while their overexpression induced apoptosis and promoted the manifestation of diabetes [12]. These are only few examples of the many miRNAs that have been reported to inhibit the expression of key $\beta$-cell genes and/or to affect specialized activities of insulin-secreting cells. Exhaustive lists of miRNAs potentially contributing to the control of $\beta$-cell functions can be found elsewhere [13, 14]. Unfortunately, many of the studies investigating the role of specific miRNAs in $\beta$-cells were carried out only in cell lines or under experimental settings that are never observed under physiological or pathophysiological conditions. Thus, although potentially informative, some of these findings await further confirmation with more appropriate experimental approaches.

\section{Involvement of miRNAs in $\beta$-cell differentiation and maturation}

Pancreatic $\beta$-cells are highly specialized cells displaying unique functional features. Differentiation of these cells occurs through a complex series of events that begins in the fetus and terminates only after weaning. There is now substantial evidence indicating that miRNAs are necessary for the differentiation of $\beta$-cells and for the acquisition of a fully mature phenotype. Indeed, pancreatic-specific deletion of Dicer 1, the gene coding for the enzyme necessary for miRNA biogenesis, results in an almost complete absence of insulin-positive cells [15]. Moreover, the conditional knockout of Dicerl in insulin-producing cells has a major impact on islet architecture and causes impaired glucose metabolism and defective insulin secretion $[16,17]$. Although the full repertoire of miRNAs involved in $\beta$-cell differentiation remains to be defined, the contribution of some specific miRNAs has already been established. Indeed, embryonic knockdown of miR-375 in zebrafish causes defects in islet morphology and scattering of the endocrine cells in the developing pancreas [18]. Moreover, re-expression of miR-375 permits to prevent dedifferentiation of human $\beta$-cells in culture [19] and the same miRNA favors the induction of insulin-producing cells from human embryonic stem cells by controlling the level of key transcription factors involved in pancreatic islet organogenesis [20]. Appropriate expression of miR-375 is also critical for fetal $\beta$-cell mass expansion. Indeed, fetuses of mothers fed with a low protein diet display increased levels of this miRNA with a consequent reduction of PDK1 expression and of the 
number of $\beta$-cells [21]. In contrast, miR-7 appears to be required for the survival of $\beta$-cells during early embryonic life. Indeed, blockade of this miRNA in mouse embryos using antisense morpholinos has a major impact on insulin production and decreases the number of $\beta$-cells, resulting in post-natal glucose intolerance [22]. Finally, embryonic induction of miR$124 \mathrm{a}$ has been proposed to contribute to the generation of $\beta$-cells by repressing the transcription factor Forkhead box A2 (FOXA2) and permitting the expression of Pdx1 [23].

While already capable of producing insulin and of releasing the hormone in response to certain secretagogues, newborn $\beta$-cells are unable to proliferate and to secrete insulin in a glucose-dependent manner until after weaning [24, 25]. Recent findings indicate that miRNAs contribute not only to the generation of insulin-expressing cells during the fetal life but participate also to the post-natal maturation of $\beta$-cells and to the acquisition of a fully mature phenotype. Newborn $\beta$-cells undergo major changes in the expression of metabolic genes permitting to acquire the capacity to respond to glucose. This gene reprogramming process is initiated by the nutritional shift occurring at weaning and is at least in part driven by changes in the expression of specific groups of miRNAs (Fig.1), including the miR-17-92 cluster and the miR-181 family [25]. Indeed, a reduction in the level of these miRNAs mimicking the modifications occurring at weaning was sufficient to render neonatal rat $\beta$-cells capable of secreting insulin in response to glucose.

\section{MiRNAs participate in the adaptation of $\beta$-cells to increased insulin needs}

The activity and the number of $\beta$-cells are constantly adjusted to match the insulin needs. Short-term exposures to a rise in circulating levels of glucose, free fatty acids or amino acids enhance the secretory activity of $\beta$-cells [1]. In case of a sustained augmentation of the insulin needs, resulting from a drop in the sensitivity of peripheral tissues, the number of $\beta$-cells is also increased. MiRNAs appear to play a critical role in this adaptive process. In fact, as mentioned above, insulin-secreting cells fail to proliferate in obese leptin-deficient $o b / o b$ mice lacking miR-375 [10]. Moreover, the compensatory expansion of the $\beta$-cell mass necessitates a reduction in the level of miR-184 and miR-338-3p. Indeed, the expression of these two miRNAs in pancreatic islets is diminished under insulin resistance conditions and blockade of miR-184 or miR-338-3p in $\beta$-cells enhance their proliferative rate both in vitro and in vivo [26-28]. There is also increasing evidence for the involvement of miR-132 in the mechanisms enabling the $\beta$-cell to face conditions necessitating the release of higher insulin quantities. In fact, the expression of this miRNA is strongly induced under insulin resistance conditions and upon exposure of the $\beta$-cells to GLP1 analogues or cAMP-raising agents [29-31]. A rise in the 
level of miR-132 improves glucose-induced insulin secretion and promotes $\beta$-cell proliferation and survival [30, 32, 33].

\section{The expression of several miRNAs is altered under diabetes conditions}

Chronic hyperglycemia and hyperlipidemia induce major changes in gene expression causing the loss of specialized $\beta$-cell functions. Prolonged exposure of $\beta$-cells to saturated fatty acids such as palmitate was reported to increase the level of miR-34a and miR-146a [34] while several other miRNAs were shown to be modulated by glucose, including miR-9, miR-30d, miR-124a, miR-130a, miR-132, miR-133, miR-212 and miR-335 [35-38]. Glucose was also found to decrease the level of miR-375 [39] but the effect of the carbohydrate on this miRNA remains controversial [36]. Alterations in miRNA expression were observed in the islets of several animal models of Type 2 diabetes, including the GK rats, $o b / o b$ and $d b / d b$ mice and mice fed a high fat diet $[10-12,28,29,32,34,36]$. Moreover, aging and the loss of compensatory $\beta$-cell mass expansion was associated with changes in the rat islet miRNA profile [40]. In addition, modifications of islet miRNA expression were observed before the onset of Type 1 diabetes in NOD mice [41, 42]. Differential expression of specific miRNAs, including miR-7a, miR-124a, miR-187 and a cluster of miRNAs produced from an imprinted locus on chromosome $14 \mathrm{q} 32$, was also detected in the islets of human donors suffering from Type 2 diabetes [11, 43-45]. When reproduced in isolated $\beta$-cells, many of the changes in miRNA expression observed under diabetes conditions resulted in impaired insulin secretion and/or a decrease in cell survival, suggesting that the alterations in the miRNA profile contribute to $\beta$-cell failure and to the development of the disease.

\section{Novel miRNA tasks}

Beside their classical functions accomplished inside the cells producing them, few years ago, the role of miRNAs took another dimension with the discovery of the presence of these small RNAs in different biological fluids either in association with proteins [46] or lipoproteins [47] or packaged inside extracellular vesicles [48]. A large proportion of plasma miRNAs was found to be associated with ribonucleoprotein complexes, but a subset of specific miRNAs was detected only in microvesicles [46]. Nearly all cell types investigated so far were found to release microvesicles containing miRNAs that can be transferred in active form to recipient cells $[48,49]$. Therefore, circulating miRNAs are now viewed as essential components of a new cell-to-cell communication mode whose rules and limitations remain to be defined. 
Mammalian cells can release several types of vesicles, including exosomes, microvesicles and apoptotic bodies that possess distinct sizes and cargo composition and are probably involved in different biological processes [50]. Because of the rapid progress in the field and the exponential increase in the number of published articles, there is a lack of consensus in the isolation methods and in the microvesicle nomenclature. In this review, we will focus on exosome-like microvesicles (also called exosomes or exosome-like vesicles) that are isolated by ultracentrifugation. They are characterized by a diameter smaller than $200 \mathrm{~nm}$ and the presence of characteristic markers such as tetraspanins (CD63, CD9 or CD81), Alix or TSG101. Exosomes originate from the late endosomal pathway and are secreted in the extracellular space upon fusion of multivesicular bodies with the plasma membrane [50]. The biogenesis and release of exosomes have been shown to involve different components of the ceramide pathway and of the ESCRT and exocytotic machinery [51-53]. Once released in the circulation, exosomes can 1) bind to receptors such as toll-like receptors on recipient cells, 2) fuse with the plasma membrane of the target cells and deliver their cargo in the cytoplasm or 3) be internalized and merge with endosomes to undergo transcytosis or to be targeted for degradation [54] (Fig.2). Exosomes can travel in body fluids over long distances and carry proteins and nucleic acids that can be transferred to recipient cells $[48,55]$. Thus, the study of these extracellular vesicles promises not only to improve the understanding of the mechanisms underlying intercellular and inter-organ communication but opens also new perspectives for the discovery of disease biomarkers.

The interest for exosomes has gained also the diabetes field [56]. Different research groups observed the release of exosome-like microvesicles from mouse, rat and human islets and from different $\beta$-cell lines [57-62]. The analysis of the content of $\beta$-cell exosomes revealed the presence of both proteins and miRNAs [58-60]. Interestingly, the exosomal cargo differs when $\beta$-cell lines are treated with cytokines, suggesting that the signals carried by these extracellular vesicles contribute to the changes in $\beta$-cell activities observed under inflammatory conditions $[58,60]$. Incubation of MIN6 or mouse-islet cells in the presence of exosomes isolated from the culture media of cytokine-treated $\beta$-cells did not affect insulin secretion but was found to trigger apoptosis [58]. To investigate whether this effect is linked to the transfer of miRNAs, a $C$. Elegans miRNA was transfected in MIN6 cells. This exogenous miRNA was indeed transferred via exosomes to untransfected MIN6 recipient cells. In addition, down-regulation in recipient cells of Ago2, a protein essential for the 
repressive activities of miRNAs, prevented apoptosis induced by exosomes released from cytokine-treated cells [58].

The effect of cytokines such as IL-1 $\beta$, TNF $\alpha$ and IFN $\gamma$ on $\beta$-cells is concentration dependent. In fact, high levels of these inflammatory mediators induce apoptosis whereas low doses stimulate $\beta$-cell function and survival $[63,64]$. With this concept in mind, Zhu and colleagues [62] demonstrated that the exosomes isolated from the culture media of INS1 cells treated with low concentrations of cytokines protect recipient $\beta$-cells from cytokine-induced apoptosis. The mechanism responsible for this protective effect was suggested to involve the release of exosomes containing the neutral ceramidase, a membrane-bound enzyme known to promote cell survival, the generation of sphingosine 1-phosphate in recipient cells and its interaction with S1P receptor 2. The functional impact of exosomes produced in response to higher doses of cytokines was not investigated in this study, neither the potential involvement of miRNAs. However, taken together these two studies suggest that the dual effect of cytokines may be linked to differences in the content of the exosomes released by $\beta$-cells, which would result either in protective or deleterious effects on recipient $\beta$-cells. If confirmed, this hypothesis would point to a concerted response to inflammatory mediators of $\beta$-cells located within the same islet.

The exosomes released by $\beta$-cells can have an impact on the activity and/or survival of other cell types. During Type 1 diabetes development, immune cells infiltrate the islets and trigger the autoimmune destruction of the $\beta$-cells. In an attempt to elucidate the events eliciting the auto-immune attack, Sheng and colleagues [61] discovered that exosomes isolated from MIN6 cells stimulate the production of inflammatory cytokines by splenocytes, induce lymphocyte proliferation and activate autoreactive T-helper 1 cells. Moreover, intravenous injection of these exosomes in NOR mice favored lymphocyte infiltration and increased insulitis. In a follow-up study, MIN6 exosomes were found to stimulate marginal zone-like B cells and to trigger both innate and antigen-specific signals, an effect associated with diabetes onset in NOD mice [65]. They also observed that exosomes from mesenchymal stem cell-like cells derived from the islets of NOD mice are highly immunostimulatory and activate autoreactive $\mathrm{B}$ and $\mathrm{T}$ cells as well as antigen-presenting cells [66]. As was the case for the exosomes from MIN6 cells, injection of exosomes from mesenchymal stem cell-like cells in NOD mice enhanced insulitis. The authors hypothesized that abnormal or excess release of exosomes from islet mesenchymal stem cell-like cells initiates the autoimmune response in NOD mice. 
In the context of islet transplantation, the cross-talk between pancreatic and endothelial cells is critical to allow graft vascularization and sustain $\beta$-cell function. Figlioni and colleagues [57] observed that extracellular vesicles isolated from conditioned media of human islets are internalized by islet endothelial cells, leading to the transfer of different mRNAs and miRNAs. This enhanced proliferation and migration of recipient endothelial cells and improved their resistance to apoptosis. Of interest, the exosomes released by human islets were found to carry a subclass of miRNAs known as angiomiR (miR-27b, miR-126, miR-130 and miR-296) which promote angiogenesis by stimulating the release of several endothelial cell growth factors. However, the precise mechanisms through which miRNAs or other extracellular vesicle components favor endothelial integrity and function remain to be established. In the other way around, Cantaluppi et al. [67] investigated the angiogenic potential of microvesicles isolated from human endothelial progenitor cells (EPC) on islet grafts. In vivo, these microvesicles favored revascularization of human islets transplanted subcutaneously in SCID mice. In vitro, EPC microvesicles stimulated insulin secretion and survival of human $\beta$-cells and promoted proliferation, migration and resistance to apoptosis of islet endothelial cells and their organization in vessel-like structures. Interestingly, EPC microvesicles were found to carry two proangiogenic miRNAs, miR-126 and miR-296, and EPC microvesicles derived from Dicer knockout animals displayed reduced angiogenic effects, confirming a relevant contribution of miRNA transfer on islet revascularization and function [67].

In addition to the described paracrine effects, exosomes and their miRNA cargo may potentially affect the activity of distant cells. A crosstalk between $\beta$-cells and insulinresponding tissues is an essential prerequisite to maintain blood glucose homeostasis. Failure in this inter-organ communication can result in the release of insufficient insulin to cover the organism needs and to the development of Type 2 diabetes. Several proteins, including, hormones, cytokines and chemokines are known to form a signaling network connecting $\beta$ cells to adipose tissue, skeletal muscles and liver. The role of these extracellular vesicles in intercellular communication is just starting to emerge. Skeletal muscles from mice fed with a lipid-enriched diet were found to release more exosomes than those of mice on a regular chow diet and were able to transfer the deleterious effects of fatty acids between muscle cells. Injection in the mouse tail vein of labelled exosomes originating from muscle cells led to their accumulation in several organs including liver, spleen, lung and pancreas [68]. Analogous findings were obtained by Jalabert et al. [69] that showed that muscle-released exosomes are 
taken up by the pancreas within $24 \mathrm{~h}$. Interestingly, intramuscular injection of labelled muscle exosomes resulted in a different biodistribution compared to intravenous delivery and was accompanied with a reduced accumulation in liver and spleen while the deposit in muscle, pancreas, kidneys and gastrointestinal tract was enhanced. These results suggest that exosomes released by muscle cells can target other insulin-sensitive tissues as well as the pancreas. In vitro experiments revealed that exosomes from GFP transfected muscle cells are taken up by MIN6 cells and can transfer their cargo. Indeed, upon incubation with muscleexosomes, GFP and the muscle-specific miR-206 were detected in MIN6 cells. To investigate if the insulin-resistant state of skeletal muscles can be signaled to $\beta$-cells, MIN6 and mouseislet cells were incubated with exosomes released ex vivo by skeletal muscles isolated from mice fed for 16 weeks on a standard diet or a diet rich in palmitate, a saturated fatty acid known to be involved in insulin resistance. Of note, $\beta$-cells exposed to exosomes produced from mice on a high-palmitate diet displayed a higher proliferation rate, potentially explaining the increased islet size observed in the mice fed with the lipid-rich diet. The exosomes produced from animals on a high-palmitate diet caused a rise of miR-16 in MIN6 cells and a concomitant downregulation of Ptchl expression, providing a potential explanation for the induction of $\beta$-cell proliferation. Taken together, these results suggest that exosomes from insulin-resistant skeletal muscles permit the transfer of miRNAs to $\beta$-cells, favoring their compensatory response to a pre-diabetic state. Additional in vitro and in vivo studies will be needed to better define the importance of this miRNA-mediated crosstalk between skeletal muscles and pancreatic $\beta$-cells.

Despite the fact that liver and adipose tissues liberate microvesicles in the circulation, there is currently no available information about their possible impact on $\beta$-cell function [7073]. Of interest, the release of miRNAs and exosomes from these insulin-sensitive tissues is increased under conditions of excess of lipids. Wang and colleagues [74] reported that the level of circulating miR-130b correlates with the body-mass index of obese individuals. This miRNA was also higher in blood, in adipocytes and, to a lesser extent, in muscles of obese mouse models. Interestingly, miR-130b was found to be released by the fat tissue and to be transferred to muscle cells were it represses the peroxisome proliferator-activated receptor $\gamma$ coactivator-1 $\alpha(\mathrm{PGC1} \alpha)$, leading to a reduction in the expression of genes controlling the oxidative capacity [74]. These results suggest that miR-130b mediates a crosstalk between the adipocytes and muscle cells. The adipose tissue of mice fed high-fat diet or of $o b / o b$ mice release also larger amounts of exosomes compared to control animals [70]. The exosomes 
derived from fat tissue of $o b / o b$ mice are taken up by monocytes, leading to their activation and to the initiation of an inflammatory response. Moreover, injection of these exosomes in wild type mice led to the increase of plasma inflammatory cytokines and to the development of glucose intolerance and insulin resistance [70]. These effects may potentially by linked to differences in the miRNA content. Indeed, the exosomes produced from visceral adipose tissue of obese and lean individuals have been shown to display different miRNA profiles [75]. In liver, the production of microvesicles from mouse, rat and human hepatocytes is stimulated upon exposure to palmitate but not following incubation with the unsaturated fatty acid oleate [71]. In agreement with these observations, the blood of mice fed on a Western diet contain higher amounts of hepatocyte-derived microvesicles compared to mice kept on a regular chow diet. The microvesicles produced by the hepatocytes under lipotoxic conditions were found to transport the protein TRAIL that leads to the activation of macrophages and triggers pro-inflammatory responses. Collectively, these findings suggest that the lipotoxic conditions associated with obesity and Type 2 diabetes can affect the number and the content of the microvesicles released by hepatocytes and adipocytes resulting in functional changes in the recipient cells and in major systemic effects. Future studies investigating the potential impact of liver and fat miRNAs and exosomes on $\beta$-cell function will help understanding whether this communication mode contributes to the adaptive response to insulin resistance conditions.

\section{Circulating miRNAs as potential biomarkers of $\beta$-cell mass and/or function?}

Besides being major regulators of gene expression, circulating miRNAs are now viewed as a novel generation of biomarkers to monitor the development of several diseases, including Type 1 and Type 2 diabetes [76-79]. The advantages of using circulating miRNAs as biomarkers include convenient non-invasive methods for sample collection from different body fluids such as blood, urine, saliva and breast milk and high resistance to harsh laboratory conditions enabling long-term storage of the samples. However, it is very difficult to determine the precise origin of most circulating miRNAs and the level of the same miRNA is often affected by numerous physiological and pathophysiological conditions [80, 81]. $\beta$-cells constitute only a tiny fraction of the cells in our body and their contribution to the plasma miRNA profile is most probably marginal. Indeed, although very abundant in islet cells and highly enriched in the endocrine pancreas compared to other tissues, only about $1 \%$ of circulating miR-375 was estimated to originate from $\beta$-cells [82]. Erener and colleagues [83] 
attempted to monitor the loss of $\beta$-cells during the initial steps of diabetes development by measuring the level of miR-375 in plasma samples of two models of Type 1 diabetes, the NOD and streptozotocin-treated mice. In both models, circulating miR-375 levels were significantly increased prior to hyperglycemia and diabetes onset, probably reflecting massive $\beta$-cell death. A rise in miR-375 plasma levels in streptozotocin-treated mice as well as in hyperglycemic $d b / d b$ mice lacking the leptin receptor was also observed in an independent study [82]. However, the circulating levels of this miRNA were decreased in two pre-diabetic but still normoglycemic animal models that are characterized by a strong expansion of the $\beta$ cell mass, the $o b / o b$ mice and mice fed high-fat diet. miR-375 levels were also found to be higher in Type 1 diabetes patients, but not in MODY (Maturity Onset Diabetes of the Young) and in Type 2 diabetic patients compared to control subjects with no metabolic disorder. Taken together, these results suggest that a rise in the plasma levels of miR-375 can be a good indicator of acute $\beta$-cell destruction, but cannot be used as a faithful reflection of $\beta$-cell function or mass. Additional studies are needed to determine if particular miRNAs coming from islet cells can mirror the loss of $\beta$-cell function and/or mass preceding the onset of Type 2 diabetes. Other alternative strategies may turn out to be more fruitful as the design of approaches to specifically isolate the exosomes released by $\beta$-cells or the measurement of other non-coding RNA classes, such as the long non-coding RNAs, that are also carried by blood vesicles and are likely to display a higher cell specificity [84].

\section{Open questions and future directions}

The discovery of miRNAs has added a new layer of complexity to the mechanisms regulating the activities of the $\beta$-cells. Thanks to intensive efforts, our knowledge about the contribution of these non-coding RNAs in the differentiation and in the control of specialized functions of insulin-secreting cells is continuously improving. However, so far we have probably only scratched the surface of the problem and many aspects concerning the role of miRNAs remain to be elucidated. The studies carried out during the last decade were based on the assumption that changes in miRNA level are paralleled by corresponding modifications in miRNA activity and vice versa. We now know that this is not necessarily the case. In fact, only a small fraction of the miRNAs is bound to Ago2 [85] and in primary tissues most of them are associated with inactive low molecular weight Ago2 complexes [86]. This inactive miRNA reservoir can be recruited to high molecular weight complexes engaged on target repression upon activation of the phosphoinositide 3-kinase/AKT or of the mTOR signaling pathways. 
These findings indicate that the level of a given miRNA is not always predictive of his repressive activity. Thus, some of the changes in miRNA expression observed in the islets of diabetic animals may be without consequence for the $\beta$-cells while the silencing activity of other miRNAs may be induced without detectable modifications in the level of the noncoding RNAs.

Another aspect that has been largely neglected is the compartmentalization of certain miRNAs within the cells. In fact, miRNAs are usually viewed as cytosolic molecules. However, several miRNAs, including miRNAs that play important roles in $\beta$-cell physiology, are present in other subcellular compartments including the mitochondria and the nucleus where they may accomplish specific and still incompletely understood regulatory tasks going beyond translational silencing (Fig.3) [87-89]. Moreover, there is emerging evidence for the association of specific miRNAs with the endoplasmic reticulum, the Golgi complex and multivesicular bodies, possibly explaining the selective release of some miRNAs from the cells [87, 90]. The subcellular distribution of the miRNAs is probably regulated by the association with components of the miRNA-induced silencing complex, including Ago family members and the Ago-binding protein GW182. The phosphorylation of these proteins can modify their localization and is likely to drive the targeting of the miRNAs to specific organelles. Because of their compartmentalization certain miRNAs may be unable to interact with a subset of their potential targets strongly affecting their repressive activity.

Another important factor that may influence the availability of the miRNAs is their capacity to interact with other RNA species such as long non-coding RNAs and circular RNAs (Fig.3). The presence of multiple binding sites in these molecules has been proposed to sequester specific miRNAs and to prevent their interaction with endogenous targets [91]. For instance CiRS-7, a circular RNA that is expressed also in $\beta$-cells [92], contains over 60 conserved binding sites for miR-7 and could potentially affect the availability of this important miRNA. Stoichiometric considerations and mathematical modeling indicate that efficient target competition can only be achieved for miRNA families displaying particular miRNA:target ratios $[93,94]$. However, this general rule may have to be reconsidered in case of compartmentalization of the miRNAs, of their targets or of the competing RNAs.

These findings about the distribution and the mode of action of the miRNAs emphasize the need for novel experimental strategies permitting to monitor the changes in the activities rather than in the level of specific miRNAs. These approaches would provide a more 
reliable picture of the contribution of these non-coding RNAs in the regulation of $\beta$-cell functions.

Different issues about the role of miRNAs in intercellular communication remain also to be addressed. A key unsolved question concerns the process controlling the loading of miRNAs inside exosomes for subsequent release. Several studies have demonstrated major differences between the exosomal miRNA profile and the repertoire of the parental cells [48, 55, 57, 58, 95]. Moreover, the exosomal miRNA content can be selectively modified in response to physiological or pathological conditions $[58,69,75]$. This clearly points to the existence of sophisticated mechanisms permitting the retention of specific miRNAs inside the cells and the packaging of others in exosomes for extracellular release (Fig.2). Different mechanisms have been proposed to explain the preferential release of certain miRNAs, but this issue has not yet been addressed in $\beta$-cells. In T lymphocytes, sumoylation has been shown to regulate the binding of the ribonucleoprotein hnRNPA2B1 to the GGAG sequence of certain miRNAs and to favor their trafficking toward exosomes [96]. In macrophages, an inverse correlation was observed between the level of the miRNAs sorted in exosomes and the cellular abundance of their respective targets, suggesting a selective release of miRNAs not involved in translational repression [97]. A different regulatory process was proposed in a study carried out in B cells in which the uridylation of the 3'end of the miRNAs was found to increase whereas the adenylation to decrease the release in exosomes [98]. Another mechanism potentially explaining the selective release of a subset of miRNAs rely on the existence of specific motifs in the 3'UTR of the target mRNAs that promote the export of mRNA/miRNA complexes into exosomes [99]. Finally, the abundance and/or the activity of two components of the miRNA silencing machinery, Ago2 and GW182, which are coreleased in exosomes was suggested to contribute to the regulation of the sorting of the miRNAs $[100,101]$. Additional studies will be required to verify these observations and to determine whether the mechanisms directing the release of miRNAs are ubiquitously conserved or are specific to each cell type.

Another important issue that will need to be addressed concerns the potential heterogeneity of the circulating exosomes. Indeed, quantitative analysis of the miRNA/exosome ratio led to the puzzling conclusion that, if distributed homogenously across the entire exosome population, even the most abundant miRNAs would be present at less than a copy per vesicle [102]. This observation would suggest that most individual exosomes are unlikely to support intercellular miRNA-based communication. However, it can be 
hypothesized that the population of exosomes released by the cells is heterogeneous and includes rare miRNA-rich vesicles carrying the signals directed to other cells. The identification and the characterization of these exosome subpopulations would significantly improve our understanding of this newly discovered intercellular communication mode.

\section{Conclusion}

More than a decade of intensive investigations have attributed to miRNAs a central place in the mechanisms regulating $\beta$-cell gene expression. We now know that these small non-coding RNAs contribute to the control of various aspects of $\beta$-cell physiology and that their dysregulation can lead to the failure of insulin-secreting cells and to the development of diabetes. Beside these well-established tasks, miRNAs are now emerging as signaling components of a new intercellular communication system and as attractive disease biomarkers. A better understanding of these newly discovered tasks will help elucidating the etiology of diabetes and will hopefully provide new tools to prevent and treat this very common metabolic disorder.

\section{Acknowledgements}

Research of the authors is supported by the Swiss National Science Foundation (Grant \#310030-146138), by the "Fondation Francophone pour la Recherche sur le Diabète" and by the European Foundation for Study of Diabetes. 


\section{References}

[1] R. Regazzi, A. Rodriguez-Trejo, C. Jacovetti, Insulin secretion in health and disease: nutrients dictate the pace, Proc Nutr Soc, 75 (2016) 19-29.

[2] P. Rorsman, E. Renstrom, Insulin granule dynamics in pancreatic beta cells, Diabetologia, 46 (2003) 1029-1045.

[3] L.J. Dominguez, M. Barbagallo, The biology of the metabolic syndrome and aging, Curr Opin Clin Nutr Metab Care, 19 (2016) 5-11.

[4] G.C. Weir, S. Bonner-Weir, Islet beta cell mass in diabetes and how it relates to function, birth, and death, Ann N Y Acad Sci, 1281 (2013) 92-105.

[5] P. Marchetti, F. Syed, M. Suleiman, M. Bugliani, L. Marselli, From genotype to human beta cell phenotype and beyond, Islets, 4 (2012) 323-332.

[6] R.A. Singer, L. Arnes, L. Sussel, Noncoding RNAs in beta cell biology, Curr Opin Endocrinol Diabetes Obes, 22 (2015) 77-85.

[7] J.L. Esguerra, L. Eliasson, Functional implications of long non-coding RNAs in the pancreatic islets of Langerhans, Front Genet, 5 (2014) 209.

[8] D.P. Bartel, MicroRNAs: target recognition and regulatory functions, Cell, 136 (2009) 215-233.

[9] M.N. Poy, L. Eliasson, J. Krutzfeldt, S. Kuwajima, X. Ma, P.E. Macdonald, S. Pfeffer, T. Tuschl, N. Rajewsky, P. Rorsman, M. Stoffel, A pancreatic islet-specific microRNA regulates insulin secretion, Nature, 432 (2004) 226-230.

[10] M.N. Poy, J. Hausser, M. Trajkovski, M. Braun, S. Collins, P. Rorsman, M. Zavolan, M. Stoffel, miR-375 maintains normal pancreatic alpha- and beta-cell mass, Proc Natl Acad Sci U S A, 106 (2009) 5813-5818.

[11] M. Latreille, J. Hausser, I. Stutzer, Q. Zhang, B. Hastoy, S. Gargani, J. Kerr-Conte, F. Pattou, M. Zavolan, J.L. Esguerra, L. Eliasson, T. Rulicke, P. Rorsman, M. Stoffel, MicroRNA-7a regulates pancreatic beta cell function, J Clin Invest, 124 (2014) 2722-2735.

[12] B.F. Belgardt, K. Ahmed, M. Spranger, M. Latreille, R. Denzler, N. Kondratiuk, F. von Meyenn, F.N. Villena, K. Herrmanns, D. Bosco, J. Kerr-Conte, F. Pattou, T. Rulicke, M. Stoffel, The microRNA-200 family regulates pancreatic beta cell survival in type 2 diabetes, Nat Med, 21 (2015) 619-627.

[13] S. Ozcan, microRNAs in Pancreatic beta-Cell Physiology, Adv Exp Med Biol, 887 (2015) 101117.

[14] C. Guay, R. Regazzi, Role of islet microRNAs in diabetes: which model for which question?, Diabetologia, 58 (2015) 456-463.

[15] F.C. Lynn, P. Skewes-Cox, Y. Kosaka, M.T. McManus, B.D. Harfe, M.S. German, MicroRNA expression is required for pancreatic islet cell genesis in the mouse, Diabetes, 56 (2007) 2938-2945.

[16] M.S. Kanji, M.G. Martin, A. Bhushan, Dicer1 is required to repress neuronal fate during endocrine cell maturation, Diabetes, 62 (2013) 1602-1611.

[17] A.D. Mandelbaum, T. Melkman-Zehavi, R. Oren, S. Kredo-Russo, T. Nir, Y. Dor, E. Hornstein, Dysregulation of Dicer1 in Beta Cells Impairs Islet Architecture and Glucose Metabolism, Exp Diabetes Res, (2012).

[18] W.P. Kloosterman, A.K. Lagendijk, R.F. Ketting, J.D. Moulton, R.H. Plasterk, Targeted inhibition of miRNA maturation with morpholinos reveals a role for miR-375 in pancreatic islet development, PLoS Biol, 5 (2007) e203.

[19] G. Nathan, S. Kredo-Russo, T. Geiger, A. Lenz, H. Kaspi, E. Hornstein, S. Efrat, MiR-375 promotes redifferentiation of adult human beta cells expanded in vitro, PLoS ONE, 10 (2015) $\mathrm{e} 0122108$.

[20] R. Wei, J. Yang, G.Q. Liu, M.J. Gao, W.F. Hou, L. Zhang, H.W. Gao, Y. Liu, G.A. Chen, T.P. Hong, Dynamic expression of microRNAs during the differentiation of human embryonic stem cells into insulin-producing cells, Gene, 518 (2013) 246-255.

[21] O. Dumortier, C. Hinault, N. Gautier, S. Patouraux, V. Casamento, E. Van Obberghen, Maternal protein restriction leads to pancreatic failure in offspring: role of misexpressed microRNA-375, Diabetes, 63 (2014) 3416-3427.

[22] M. Nieto, P. Hevia, E. Garcia, D. Klein, S. Alvarez-Cubela, V. Bravo-Egana, S. Rosero, R. Damaris Molano, N. Vargas, C. Ricordi, A. Pileggi, J. Diez, J. Dominguez-Bendala, R.L. Pastori, 
Antisense miR-7 impairs insulin expression in developing pancreas and in cultured pancreatic buds, Cell Transplant, 21 (2012) 1761-1774.

[23] N. Baroukh, M.A. Ravier, M.K. Loder, E.V. Hill, A. Bounacer, R. Scharfmann, G.A. Rutter, E. Van Obberghen, MicroRNA-124a regulates Foxa2 expression and intracellular signaling in pancreatic beta-cells lines, J Biol Chem 282,19575-19588, (2007).

[24] M. Stolovich-Rain, J. Enk, J. Vikesa, F.C. Nielsen, A. Saada, B. Glaser, Y. Dor, Weaning triggers a maturation step of pancreatic beta cells, Dev Cell, 32 (2015) 535-545.

[25] C. Jacovetti, S.J. Matkovich, A. Rodriguez-Trejo, C. Guay, R. Regazzi, Postnatal beta-cell maturation is associated with islet-specific microRNA changes induced by nutrient shifts at weaning, Nat Commun, 6 (2015) 8084.

[26] C. Jacovetti, A. Abderrahmani, G. Parnaud, J.C. Jonas, M.L. Peyot, M. Cornu, R. Laybutt, E. Meugnier, S. Rome, B. Thorens, M. Prentki, D. Bosco, R. Regazzi, MicroRNAs contribute to compensatory beta cell expansion during pregnancy and obesity, J Clin Invest, 122 (2012) 3541-3551.

[27] C. Jacovetti, V. Jimenez, E. Ayuso, R. Laybutt, M.L. Peyot, M. Prentki, F. Bosch, R. Regazzi, Contribution of Intronic miR-338-3p and Its Hosting Gene AATK to Compensatory beta-Cell Mass Expansion, Mol Endocrinol, 29 (2015) 693-702.

[28] S.G. Tattikota, T. Rathjen, S.J. McAnulty, H.H. Wessels, I. Akerman, M. van de Bunt, J. Hausser, J.L. Esguerra, A. Musahl, A.K. Pandey, X. You, W. Chen, P.L. Herrera, P.R. Johnson, D. O'Carroll, L. Eliasson, M. Zavolan, A.L. Gloyn, J. Ferrer, R. Shalom-Feuerstein, D. Aberdam, M.N. Poy, Argonaute2 mediates compensatory expansion of the pancreatic beta cell, Cell Metab, 19 (2014) 122134.

[29] E. Zhao, M.P. Keller, M.E. Rabaglia, A.T. Oler, D.S. Stapleton, K.L. Schueler, E.C. Neto, J.Y. Moon, P. Wang, I.M. Wang, P.Y. Lum, I. Ivanovska, M. Cleary, D. Greenawalt, J. Tsang, Y.J. Choi, R. Kleinhanz, J. Shang, Y.P. Zhou, A.D. Howard, B.B. Zhang, C. Kendziorski, N.A. Thornberry, B.S. Yandell, E.E. Schadt, A.D. Attie, Obesity and genetics regulate microRNAs in islets, liver, and adipose of diabetic mice, Mamm Genome, 20 (2009) 476-485.

[30] H.A. Malm, I.G. Mollet, C. Berggreen, M. Orho-Melander, J.L. Esguerra, O. Goransson, L. Eliasson, Transcriptional regulation of the miR-212/miR-132 cluster in insulin-secreting beta-cells by cAMP-regulated transcriptional co-activator 1 and salt-inducible kinases, Mol Cell Endocrinol, (2016).

[31] J. Shang, J. Li, M.P. Keller, H.E. Hohmeier, Y. Wang, Y. Feng, H.H. Zhou, X. Shen, M. Rabaglia, M. Soni, A.D. Attie, C.B. Newgard, N.A. Thornberry, A.D. Howard, Y.P. Zhou, Induction of miR-132 and miR-212 Expression by Glucagon-Like Peptide 1 (GLP-1) in Rodent and Human Pancreatic beta-Cells, Mol Endocrinol, 29 (2015) 1243-1253.

[32] V. Nesca, C. Guay, C. Jacovetti, V. Menoud, M.L. Peyot, D.R. Laybutt, M. Prentki, R. Regazzi, Identification of particular groups of microRNAs that positively or negatively impact on beta cell function in obese models of type 2 diabetes, Diabetologia, 56 (2013) 2203-2212.

[33] M.S. Soni, M.E. Rabaglia, S. Bhatnagar, J. Shang, O. Ilkayeva, R. Mynatt, Y.P. Zhou, E.E. Schadt, N.A. Thornberry, D.M. Muoio, M.P. Keller, A.D. Attie, Downregulation of Carnitine acylcarnitine translocase by miRNAs 132 and 212 amplifies glucose-stimulated insulin secretion, Diabetes, 63 (2014) 3805-3814.

[34] P. Lovis, E. Roggli, D.R. Laybutt, S. Gattesco, J.Y. Yang, C. Widmann, A. Abderrahmani, R. Regazzi, Alterations in microRNA expression contribute to fatty acid-induced pancreatic beta-cell dysfunction, Diabetes, 57 (2008) 2728-2736.

[35] X. Tang, L. Muniappan, G. Tang, S. Ozcan, Identification of glucose-regulated miRNAs from pancreatic \{beta\} cells reveals a role for miR-30d in insulin transcription, Rna, 15 (2009) 287-293.

[36] J.L. Esguerra, C. Bolmeson, C.M. Cilio, L. Eliasson, Differential Glucose-Regulation of MicroRNAs in Pancreatic Islets of Non-Obese Type 2 Diabetes Model Goto-Kakizaki Rat, PLoS One, 6 (2011) e18613.

[37] D. Ramachandran, U. Roy, S. Garg, S. Ghosh, S. Pathak, U. Kolthur-Seetharam, Sirt1 and mir-9 expression is regulated during glucose-stimulated insulin secretion in pancreatic beta-islets, Febs Journal, 278 (2011) 1167-1174.

[38] R.G. Fred, C.H. Bang-Berthelsen, T. Mandrup-Poulsen, L.G. Grunnet, N. Welsh, High Glucose Suppresses Human Islet Insulin Biosynthesis by Inducing miR-133a Leading to Decreased Polypyrimidine Tract Binding Protein-Expression, PLoS ONE, 5 (2010). 
[39] A. El Ouaamari, N. Baroukh, G.A. Martens, P. Lebrun, D. Pipeleers, E. van Obberghen, miR-375 targets 3'-phosphoinositide-dependent protein kinase-1 and regulates glucose-induced biological responses in pancreatic beta-cells, Diabetes, 57 (2008) 2708-2717.

[40] K. Tugay, C. Guay, A.C. Marques, F. Allagnat, J.M. Locke, L.W. Harries, G.A. Rutter, R. Regazzi, Role of microRNAs in the age-associated decline of pancreatic beta cell function in rat islets, Diabetologia, (2015).

[41] E. Roggli, A. Britan, S. Gattesco, N. Lin-Marq, A. Abderrahmani, P. Meda, R. Regazzi, Involvement of microRNAs in the cytotoxic effects exerted by proinflammatory cytokines on pancreatic beta-cells, Diabetes, 59 (2010) 978-986.

[42] E. Roggli, S. Gattesco, D. Caille, C. Briet, C. Boitard, P. Meda, R. Regazzi, Changes in microRNA expression contribute to pancreatic beta-cell dysfunction in prediabetic NOD mice, Diabetes, 61 (2012) 1742-1751.

[43] V. Kameswaran, N.C. Bramswig, L.B. McKenna, M. Penn, J. Schug, N.J. Hand, Y. Chen, I. Choi, A. Vourekas, K.J. Won, C. Liu, K. Vivek, A. Naji, J.R. Friedman, K.H. Kaestner, Epigenetic regulation of the DLK1-MEG3 microRNA cluster in human type 2 diabetic islets, Cell Metab, 19 (2014) 135-145.

[44] J.M. Locke, G. da Silva Xavier, H.R. Dawe, G.A. Rutter, L.W. Harries, Increased expression of miR-187 in human islets from individuals with type 2 diabetes is associated with reduced glucosestimulated insulin secretion, Diabetologia, 57 (2014) 122-128.

[45] G. Sebastiani, A. Po, E. Miele, G. Ventriglia, E. Ceccarelli, M. Bugliani, L. Marselli, P. Marchetti, A. Gulino, E. Ferretti, F. Dotta, MicroRNA-124a is hyperexpressed in type 2 diabetic human pancreatic islets and negatively regulates insulin secretion, Acta Diabetol, 52 (2015) 523-530.

[46] J.D. Arroyo, J.R. Chevillet, E.M. Kroh, I.K. Ruf, C.C. Pritchard, D.F. Gibson, P.S. Mitchell, C.F. Bennett, E.L. Pogosova-Agadjanyan, D.L. Stirewalt, J.F. Tait, M. Tewari, Argonaute2 complexes carry a population of circulating microRNAs independent of vesicles in human plasma, Proc Natl Acad Sci U S A, 108 (2011) 5003-5008.

[47] K.C. Vickers, B.T. Palmisano, B.M. Shoucri, R.D. Shamburek, A.T. Remaley, MicroRNAs are transported in plasma and delivered to recipient cells by high-density lipoproteins, Nat Cell Biol, 13 (2011) 423-433.

[48] H. Valadi, K. Ekstrom, A. Bossios, M. Sjostrand, J.J. Lee, J.O. Lotvall, Exosome-mediated transfer of mRNAs and microRNAs is a novel mechanism of genetic exchange between cells, Nat Cell Biol, 9 (2007) 654-659.

[49] N. Kosaka, H. Iguchi, Y. Yoshioka, F. Takeshita, Y. Matsuki, T. Ochiya, Secretory mechanisms and intercellular transfer of microRNAs in living cells, J Biol Chem, 285 (2010) 17442-17452.

[50] C. Thery, M. Ostrowski, E. Segura, Membrane vesicles as conveyors of immune responses, Nat Rev Immunol, 9 (2009) 581-593.

[51] J.H. Hurley, G. Odorizzi, Get on the exosome bus with ALIX, Nat Cell Biol, 14 (2012) 654-655.

[52] M. Ostrowski, N.B. Carmo, S. Krumeich, I. Fanget, G. Raposo, A. Savina, C.F. Moita, K. Schauer, A.N. Hume, R.P. Freitas, B. Goud, P. Benaroch, N. Hacohen, M. Fukuda, C. Desnos, M.C. Seabra, F. Darchen, S. Amigorena, L.F. Moita, C. Thery, Rab27a and Rab27b control different steps of the exosome secretion pathway, Nat Cell Biol, 12 (2010) 19-30; sup pp 11-13.

[53] K. Trajkovic, C. Hsu, S. Chiantia, L. Rajendran, D. Wenzel, F. Wieland, P. Schwille, B. Brugger, M. Simons, Ceramide triggers budding of exosome vesicles into multivesicular endosomes, Science, 319 (2008) 1244-1247.

[54] J. Zhang, S. Li, L. Li, M. Li, C. Guo, J. Yao, S. Mi, Exosome and exosomal microRNA: trafficking, sorting, and function, Genomics Proteomics Bioinformatics, 13 (2015) 17-24.

[55] J. Skog, T. Wurdinger, S. van Rijn, D.H. Meijer, L. Gainche, M. Sena-Esteves, W.T. Curry, Jr., B.S. Carter, A.M. Krichevsky, X.O. Breakefield, Glioblastoma microvesicles transport RNA and proteins that promote tumour growth and provide diagnostic biomarkers, Nat Cell Biol, 10 (2008) 1470-1476.

[56] A.J. Lakhter, E.K. Sims, Minireview: Emerging Roles for Extracellular Vesicles in Diabetes and Related Metabolic Disorders, Mol Endocrinol, 29 (2015) 1535-1548.

[57] F. Figliolini, V. Cantaluppi, M. De Lena, S. Beltramo, R. Romagnoli, M. Salizzoni, R. Melzi, R. Nano, L. Piemonti, C. Tetta, L. Biancone, G. Camussi, Isolation, characterization and potential role in 
beta cell-endothelium cross-talk of extracellular vesicles released from human pancreatic islets, PLoS One, 9 (2014) e102521.

[58] C. Guay, V. Menoud, S. Rome, R. Regazzi, Horizontal transfer of exosomal microRNAs transduce apoptotic signals between pancreatic beta-cells, Cell Commun Signal, 13 (2015) 17.

[59] H.S. Lee, J. Jeong, K.J. Lee, Characterization of vesicles secreted from insulinoma NIT-1 cells, J Proteome Res, 8 (2009) 2851-2862.

[60] G. Palmisano, S.S. Jensen, M.C. Le Bihan, J. Laine, J.N. McGuire, F. Pociot, M.R. Larsen, Characterization of Membrane-shed Microvesicles from Cytokine-stimulated beta-Cells Using Proteomics Strategies, Mol Cell Proteomics, 11 (2012) 230-243.

[61] H. Sheng, S. Hassanali, C. Nugent, L. Wen, E. Hamilton-Williams, P. Dias, Y.D. Dai, Insulinoma-released exosomes or microparticles are immunostimulatory and can activate autoreactive T cells spontaneously developed in nonobese diabetic mice, J Immunol, 187 (2011) 1591-1600.

[62] Q. Zhu, J. Kang, H. Miao, Y. Feng, L. Xiao, Z. Hu, D.F. Liao, Y. Huang, J. Jin, S. He, Low-dose cytokine-induced neutral ceramidase secretion from INS-1 cells via exosomes and its anti-apoptotic effect, Febs J, 281 (2014) 2861-2870.

[63] D.L. Eizirik, T. Mandrup-Poulsen, A choice of death--the signal-transduction of immunemediated beta-cell apoptosis, Diabetologia, 44 (2001) 2115-2133.

[64] K. Maedler, D.M. Schumann, N. Sauter, H. Ellingsgaard, D. Bosco, R. Baertschiger, Y. Iwakura, J. Oberholzer, C.B. Wollheim, B.R. Gauthier, M.Y. Donath, Low concentration of interleukin-1beta induces FLICE-inhibitory protein-mediated beta-cell proliferation in human pancreatic islets, Diabetes, 55 (2006) 2713-2722.

[65] R. Bashratyan, H. Sheng, D. Regn, M.J. Rahman, Y.D. Dai, Insulinoma-released exosomes activate autoreactive marginal zone-like B cells that expand endogenously in prediabetic NOD mice, Eur J Immunol, (2013).

[66] M.J. Rahman, D. Regn, R. Bashratyan, Y.D. Dai, Exosomes released by islet-derived mesenchymal stem cells trigger autoimmune responses in NOD mice, Diabetes, 63 (2014) 1008-1020.

[67] V. Cantaluppi, L. Biancone, F. Figliolini, S. Beltramo, D. Medica, M.C. Deregibus, F. Galimi, R. Romagnoli, M. Salizzoni, C. Tetta, G.P. Segoloni, G. Camussi, Microvesicles derived from endothelial progenitor cells enhance neoangiogenesis of human pancreatic islets, Cell Transplant, 21 (2012) 1305-1320.

[68] H. Aswad, A. Forterre, O.P. Wiklander, G. Vial, E. Danty-Berger, A. Jalabert, A. Lamaziere, E. Meugnier, S. Pesenti, C. Ott, K. Chikh, S. El-Andaloussi, H. Vidal, E. Lefai, J. Rieusset, S. Rome, Exosomes participate in the alteration of muscle homeostasis during lipid-induced insulin resistance in mice, Diabetologia, 57 (2014) 2155-2164.

[69] A. Jalabert, G. Vial, C. Guay, O.P. Wiklander, J.Z. Nordin, H. Aswad, A. Forterre, E. Meugnier, S. Pesenti, R. Regazzi, E. Danty-Berger, S. Ducreux, H. Vidal, S. El-Andaloussi, J. Rieusset, S. Rome, Exosome-like vesicles released from lipid-induced insulin-resistant muscles modulate gene expression and proliferation of beta recipient cells in mice, Diabetologia, (2016).

[70] Z.B. Deng, A. Poliakov, R.W. Hardy, R. Clements, C. Liu, Y. Liu, J. Wang, X. Xiang, S. Zhang, X. Zhuang, S.V. Shah, D. Sun, S. Michalek, W.E. Grizzle, T. Garvey, J. Mobley, H.G. Zhang, Adipose tissue exosome-like vesicles mediate activation of macrophage-induced insulin resistance, Diabetes, 58 (2009) 2498-2505.

[71] P. Hirsova, S.H. Ibrahim, A. Krishnan, V.K. Verma, S.F. Bronk, N.W. Werneburg, M.R. Charlton, V.H. Shah, H. Malhi, G.J. Gores, Lipid-Induced Signaling Causes Release of Inflammatory Extracellular Vesicles From Hepatocytes, Gastroenterology, (2016).

[72] Y. Zhang, M. Yu, W. Tian, Physiological and pathological impact of exosomes of adipose tissue, Cell Prolif, (2016).

[73] F. Royo, J.M. Falcon-Perez, Liver extracellular vesicles in health and disease, J Extracell Vesicles, 1 (2012).

[74] Y.C. Wang, Y. Li, X.Y. Wang, D. Zhang, H. Zhang, Q. Wu, Y.Q. He, J.Y. Wang, L. Zhang, H. Xia, J. Yan, X. Li, H. Ying, Circulating miR-130b mediates metabolic crosstalk between fat and muscle in overweight/obesity, Diabetologia, 56 (2013) 2275-2285.

[75] S.C. Ferrante, E.P. Nadler, D.K. Pillai, M.J. Hubal, Z. Wang, J.M. Wang, H. Gordish-Dressman, E. Koeck, S. Sevilla, A.A. Wiles, R.J. Freishtat, Adipocyte-derived exosomal miRNAs: a novel mechanism for obesity-related disease, Pediatr Res, 77 (2015) 447-454. 
[76] C. Guay, R. Regazzi, Circulating microRNAs as novel biomarkers for diabetes mellitus, Nat Rev Endocrinol, 9 (2013) 513-521.

[77] A. Zampetaki, S. Kiechl, I. Drozdov, P. Willeit, U. Mayr, M. Prokopi, A. Mayr, S. Weger, F. Oberhollenzer, E. Bonora, A. Shah, J. Willeit, M. Mayr, Plasma microRNA profiling reveals loss of endothelial miR-126 and other microRNAs in type 2 diabetes, Circ Res, 107 (2010) 810-817.

[78] F.J. Ortega, J.M. Mercader, J.M. Moreno-Navarrete, O. Rovira, E. Guerra, E. Esteve, G. Xifra, C. Martinez, W. Ricart, J. Rieusset, S. Rome, M. Karczewska-Kupczewska, M. Straczkowski, J.M. Fernandez-Real, Profiling of circulating microRNAs reveals common microRNAs linked to type 2 diabetes that change with insulin sensitization, Diabetes Care, 37 (2014) 1375-1383.

[79] J. Raffort, C. Hinault, O. Dumortier, E. Van Obberghen, Circulating microRNAs and diabetes: potential applications in medical practice, Diabetologia, 58 (2015) 1978-1992.

[80] A. Keller, P. Leidinger, A. Bauer, A. Elsharawy, J. Haas, C. Backes, A. Wendschlag, N. Giese, C. Tjaden, K. Ott, J. Werner, T. Hackert, K. Ruprecht, H. Huwer, J. Huebers, G. Jacobs, P. Rosenstiel, H. Dommisch, A. Schaefer, J. Muller-Quernheim, B. Wullich, B. Keck, N. Graf, J. Reichrath, B. Vogel, A. Nebel, S.U. Jager, P. Staehler, I. Amarantos, V. Boisguerin, C. Staehler, M. Beier, M. Scheffler, M.W. Buchler, J. Wischhusen, S.F. Haeusler, J. Dietl, S. Hofmann, H.P. Lenhof, S. Schreiber, H.A. Katus, W. Rottbauer, B. Meder, J.D. Hoheisel, A. Franke, E. Meese, Toward the blood-borne miRNome of human diseases, Nat Methods, 8 (2011) 841-843.

[81] D.P. Tonge, T.W. Gant, What is normal? Next generation sequencing-driven analysis of the human circulating miRNAOme, BMC Mol Biol, 17 (2016) 4.

[82] M. Latreille, K. Herrmanns, N. Renwick, T. Tuschl, M.T. Malecki, M.I. McCarthy, K.R. Owen, T. Rulicke, M. Stoffel, miR-375 gene dosage in pancreatic beta-cells: implications for regulation of beta-cell mass and biomarker development, J Mol Med (Berl), 93 (2015) 1159-1169.

[83] S. Erener, M. Mojibian, J.K. Fox, H.C. Denroche, T.J. Kieffer, Circulating miR-375 as a biomarker of beta-cell death and diabetes in mice, Endocrinology, 154 (2013) 603-608.

[84] Y. Yang, Y. Cai, G. Wu, X. Chen, Y. Liu, X. Wang, J. Yu, C. Li, P.A. Jose, L. Zhou, C. Zeng, Plasma long non-coding RNA, CoroMarker, a novel biomarker for diagnosis of coronary artery disease, Clin Sci (Lond), 129 (2015) 675-685.

[85] O. Flores, E.M. Kennedy, R.L. Skalsky, B.R. Cullen, Differential RISC association of endogenous human microRNAs predicts their inhibitory potential, Nucleic Acids Res, 42 (2014) 46294639 .

[86] G. La Rocca, S.H. Olejniczak, A.J. Gonzalez, D. Briskin, J.A. Vidigal, L. Spraggon, R.G. DeMatteo, M.R. Radler, T. Lindsten, A. Ventura, T. Tuschl, C.S. Leslie, C.B. Thompson, In vivo, Argonaute-bound microRNAs exist predominantly in a reservoir of low molecular weight complexes not associated with mRNA, Proc Natl Acad Sci U S A, 112 (2015) 767-772.

[87] A.K. Leung, The Whereabouts of microRNA Actions: Cytoplasm and Beyond, Trends Cell Biol, 25 (2015) 601-610.

[88] T.C. Roberts, The MicroRNA Biology of the Mammalian Nucleus, Mol Ther Nucleic Acids, 3 (2014) e188.

[89] P.M. Borralho, C.M. Rodrigues, C.J. Steer, microRNAs in Mitochondria: An Unexplored Niche, Adv Exp Med Biol, 887 (2015) 31-51.

[90] Y.J. Kim, A. Maizel, X. Chen, Traffic into silence: endomembranes and post-transcriptional RNA silencing, Embo J, 33 (2014) 968-980.

[91] Y. Tay, J. Rinn, P.P. Pandolfi, The multilayered complexity of ceRNA crosstalk and competition, Nature, 505 (2014) 344-352.

[92] H. Xu, S. Guo, W. Li, P. Yu, The circular RNA Cdr1as, via miR-7 and its targets, regulates insulin transcription and secretion in islet cells, Sci Rep, 5 (2015) 12453.

[93] R. Denzler, V. Agarwal, J. Stefano, D.P. Bartel, M. Stoffel, Assessing the ceRNA hypothesis with quantitative measurements of miRNA and target abundance, Mol Cell, 54 (2014) 766-776.

[94] A.D. Bosson, J.R. Zamudio, P.A. Sharp, Endogenous miRNA and target concentrations determine susceptibility to potential ceRNA competition, Mol Cell, 56 (2014) 347-359.

[95] E.N. Nolte-'t Hoen, H.P. Buermans, M. Waasdorp, W. Stoorvogel, M.H. Wauben, P.A. t Hoen, Deep sequencing of RNA from immune cell-derived vesicles uncovers the selective incorporation of small non-coding RNA biotypes with potential regulatory functions, Nucleic Acids Res, 40 (2012) 9272-9285. 
[96] C. Villarroya-Beltri, C. Gutierrez-Vazquez, F. Sanchez-Cabo, D. Perez-Hernandez, J. Vazquez, N. Martin-Cofreces, D.J. Martinez-Herrera, A. Pascual-Montano, M. Mittelbrunn, F. Sanchez-Madrid, Sumoylated hnRNPA2B1 controls the sorting of miRNAs into exosomes through binding to specific motifs, Nat Commun, 4 (2013) 2980.

[97] M.L. Squadrito, C. Baer, F. Burdet, C. Maderna, G.D. Gilfillan, R. Lyle, M. Ibberson, M. De Palma, Endogenous RNAs Modulate MicroRNA Sorting to Exosomes and Transfer to Acceptor Cells, Cell Rep, 8 (2014) 1432-1446.

[98] D. Koppers-Lalic, M. Hackenberg, I.V. Bijnsdorp, M.A. van Eijndhoven, P. Sadek, D. Sie, N. Zini, J.M. Middeldorp, B. Ylstra, R.X. de Menezes, T. Wurdinger, G.A. Meijer, D.M. Pegtel, Nontemplated nucleotide additions distinguish the small RNA composition in cells from exosomes, Cell Rep, 8 (2014) 1649-1658.

[99] M.F. Bolukbasi, A. Mizrak, G.B. Ozdener, S. Madlener, T. Strobel, E.P. Erkan, J.B. Fan, X.O. Breakefield, O. Saydam, miR-1289 and "Zipcode"-like Sequence Enrich mRNAs in Microvesicles, Mol Ther Nucleic Acids, 1 (2012) e10.

[100] D.J. Gibbings, C. Ciaudo, M. Erhardt, O. Voinnet, Multivesicular bodies associate with components of miRNA effector complexes and modulate miRNA activity, Nat Cell Biol, 11 (2009) $1143-1149$.

[101] J. Guduric-Fuchs, O.C. A, B. Camp, C.L. O'Neill, R.J. Medina, D.A. Simpson, Selective extracellular vesicle-mediated export of an overlapping set of microRNAs from multiple cell types, BMC Genomics, 13 (2012) 357.

[102] J.R. Chevillet, Q. Kang, I.K. Ruf, H.A. Briggs, L.N. Vojtech, S.M. Hughes, H.H. Cheng, J.D. Arroyo, E.K. Meredith, E.N. Gallichotte, E.L. Pogosova-Agadjanyan, C. Morrissey, D.L. Stirewalt, F. Hladik, E.Y. Yu, C.S. Higano, M. Tewari, Quantitative and stoichiometric analysis of the microRNA content of exosomes, Proc Natl Acad Sci U S A, 111 (2014) 14888-14893.

[103] T.J. Pullen, G.D. Xavier, G. Kelsey, G.A. Rutter, miR-29a and miR-29b Contribute to Pancreatic beta-Cell-Specific Silencing of Monocarboxylate Transporter 1 (Mct1), Molecular and Cellular Biology, 31 (2011) 3182-3194. 


\section{Figure legends}

Fig.1) MiRNAs control the expression of key metabolic genes. Mature pancreatic $\beta$-cells express a particular repertoire of genes involved in glucose metabolism. They contain high levels of glycolytic enzymes and of mitochondrial shuttles (Gpd2 and $M d h 1)$ that permit a tight coupling between glucose metabolism and insulin secretion. The expression of several of these genes are controlled by miRNAs (in yellow) that are down-regulated during the postnatal maturation of the $\beta$-cells [25]. In contrast, fully differentiated $\beta$-cells express extremely low levels of $L d h 1$ and Mctl, preventing the generation and the uptake of lactate. One of the miRNAs that is up-regulated during the maturation of the $\beta$-cells, miR-29 (in blue) contributes to the silencing of Mctl [25, 103].

Fig.2) miRNA biogenesis and function. 1) Precursor miRNAs (pre-miRNAs), produced by the Drosha complex, are transported from the nucleus to the cytoplasm by exportin-5 where they are cleaved by Dicer to form imperfect miRNA duplexes. Mature miRNA strands are then loaded on RNA-induced silencing complex (RISC) in association with Ago2. The RISC complex guided by the mature miRNA binds to the 3'untranslated region (3'UTR) of target mRNAs and represses their translation. 2) miRNAs can also be sorted toward exosomes and be released by the cell upon fusion of multivesicular bodies (MVB) with the plasma membrane. 3) The released miRNAs can interact with recipient cells by binding to a receptor or be taken up in active form by endocytosis or by fusion of exosomes with the plasma membrane.

Fig.3) Factors controlling the distribution and the availability of the miRNAs for target interaction. Many miRNAs can be found not only in the cytosol but also in other subcellular compartments, including the nucleus, the mitochondria, the endoplasmic reticulum (ER), the Golgi apparatus and the multivesicular bodies. Moreover, a fraction of the miRNAs can be sequestered by circular RNAs (circRNAs) or by long non-coding RNAs (lncRNAs) containing multiple high affinity miRNA binding sites. The compartmentalization of part of the miRNAs is likely to affect their capacity to interact with certain targets and may be required to accomplish some organelle-specific tasks. 


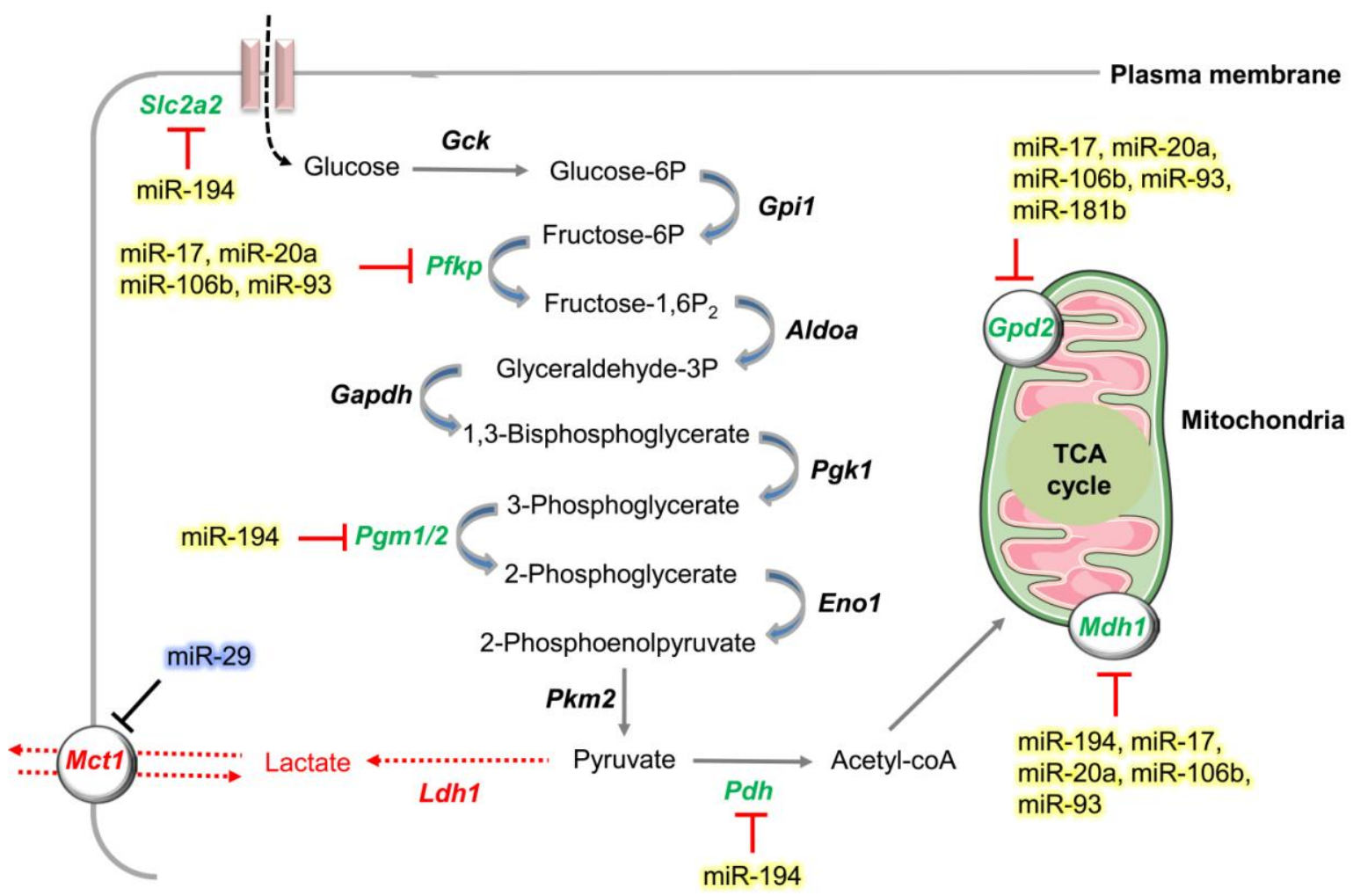




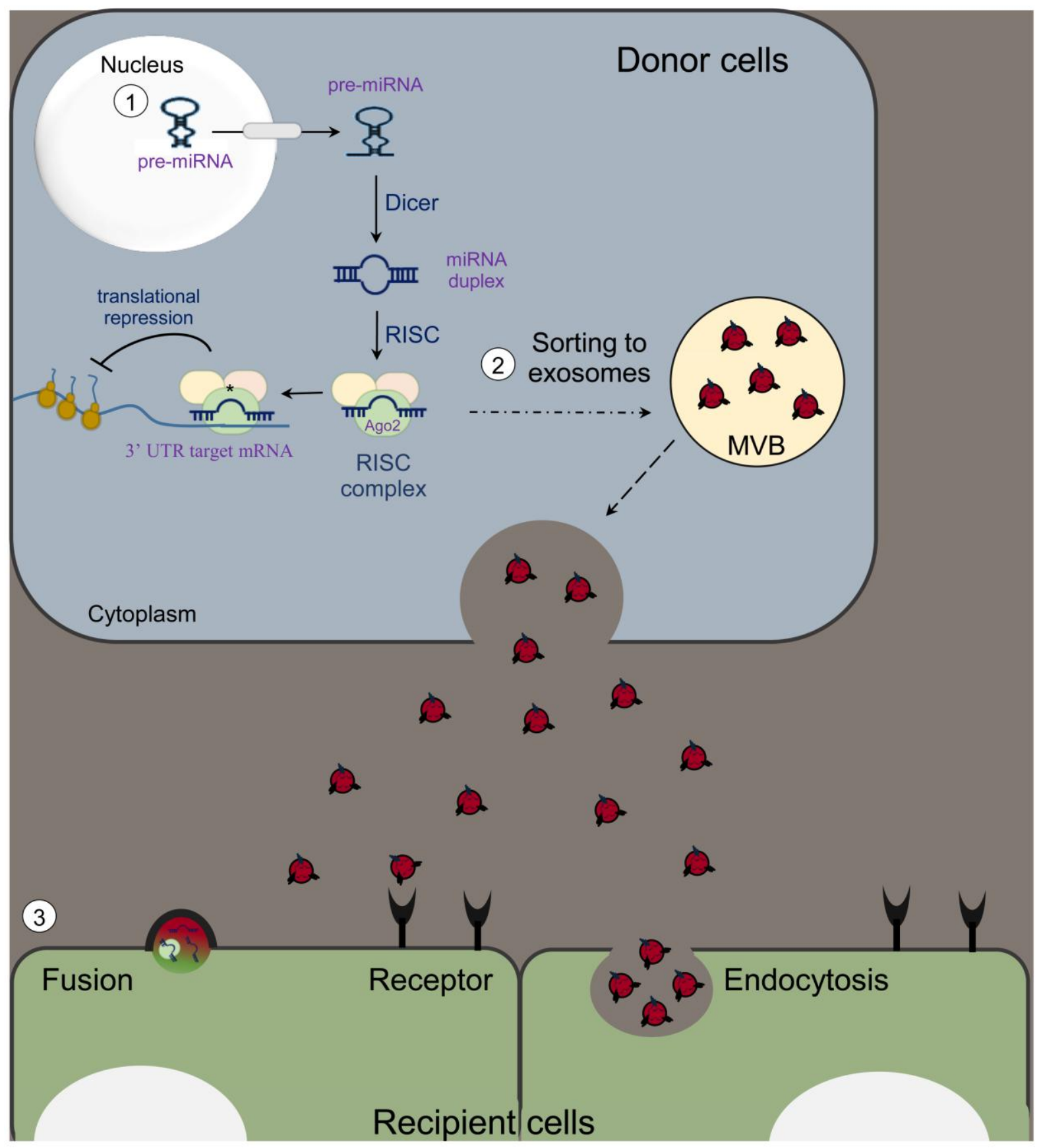




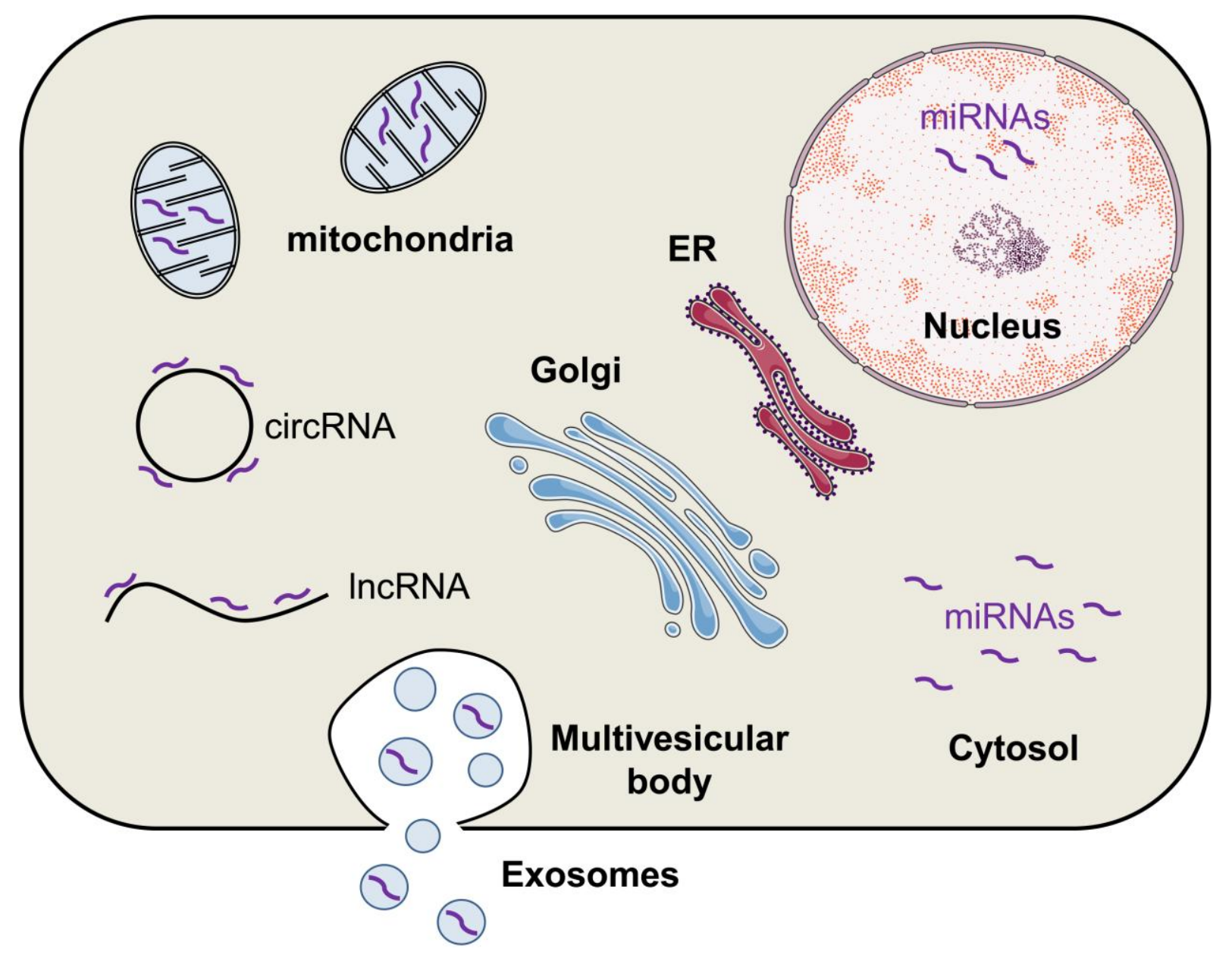

